\title{
La intervención municipal sobre la distribución gratuita de prensa en la vía pública *
}

\author{
José Vida Fernández \\ Profesor de Derecho Administrativo \\ Universidad Carlos III de Madrid
}

\begin{abstract}
Sumario:1. PLANTEAMIENTO Y DELIMITACIÓN DEL FENÓMENO DE LA PRENSA DE DISTRIBUCIÓN GRATUITA. 1.1. La proliferación de la prensa gratuita y el problema de su distribución. 1.2. Delimitación del concepto de prensa de distribución gratuita e identificación de las publicaciones así consideradas. 1.3 Descripción del régimen jurídico de la prensa de distribución gratuita.- 2. FUNDAMENTO Y ANÁLISIS DEL RÉGIMEN JURÍDICO DE LA INTERVENCIÓN MUNICIPAL SOBRE LA ACTIVIDAD DE DISTRIBUCIÓN GRATUITA DE PRENSA EN LA VÍA PÚBLICA. 2.1. Fundamento y descripción del régimen jurídico de la intervención municipal sobre la distribución gratuita de prensa en la vía pública. 2.2. Distinción de la intervención municipal sobre otras actividades distintas a la distribución gratuita de prensa en la vía pública. 2.3. Sistematización de la regulación municipal existente de la distribución gratuita de prensa en la vía pública.- 3. ANÁLISIS DE LA INTERVENCIÓN MUNICIPAL SOBRE LA DISTRIBUCIÓN GRATUITA DE PRENSA EN LA VÍA PÚBLICA. 3.1. Actividad objeto de regulación y sujetos implicados. 3.2. Elementos espaciales: superficie ocupada y distancias de los emplazamientos. 3.3. Elementos temporales: días y horas de reparto. 3.4. Elementos funcionales: desarrollo de la actividad de distribución y reparto. 3.5. Derechos y obligaciones de los titulares de las licencias. 3.6 Otorgamiento, duración y extinción de las licencias. 3.7. Régimen sancionador.- 4. EL EQUILIBRIO ENTRE LA INTERVENCIÓN MUNICIPAL SOBRE LA DISTRIBUCIÓN GRATUITA DE PRENSA Y EL EJERCICIO DE LOS DERECHOS FUNDAMENTALES DE LA COMUNICACIÓN.
\end{abstract}

\section{PLANTEAMIENTO Y DESCRIPCIÓN DEL FENÓMENO DE LA PRENSA DE DISTRIBUCIÓN GRATUITA}

\subsection{La proliferación de la prensa gratuita y el problema de su distribución}

La llamada prensa gratuita se ha convertido en la última década en una alternativa dentro de los medios de comunicación por la que optan cada día millones de personas. Las publicaciones gratuitas y, en particular, los diarios gratuitos, han abandonado su condición de publicaciones menores, marginales o advenedizas dentro de la prensa escrita, situándose junto a los principa-

\footnotetext{
* El presente trabajo se ha desarrollado dentro del Proyecto BJU2002-03794 «Liberalización, competencia y cohesión social: tres nuevos retos del Derecho Administrativo» del Programa de Investigación del Ministerio de Ciencia y Tecnología, desarrollado en la Universidad Carlos III de Madrid y dirigido por el Prof. Dr. D. Tomás de la Quadra-Salcedo Fernández del Castillo.
} 
les diarios de pago en cuanto a su relevancia y aceptación social. De hecho, han llegado incluso a desbancarlos en el número de lectores ${ }^{1}$, alcanzando a grupos de población que, por diversas circunstancias, no eran lectores de publicaciones periódicas, y cubriendo, asimismo, ámbitos de información escasamente tratados por publicaciones profesionales como son el local, infralocal y especializado ${ }^{2}$.

A pesar del enorme crecimiento experimentado se han mantenido intactas sus singularidades originarias que las distinguen de las demás publicaciones periódicas, como son la financiación a través de la publicidad y su consiguiente distribución con carácter gratuito en lugares públicos.

Precisamente la multiplicación en el numero de este tipo de publicaciones y el crecimiento exponencial de los ejemplares distribuidos han planteado la necesidad de establecer una regulación específica por parte de los poderes públicos, en particular por lo que se refiere a su distribución en la vía y espacios públicos. La avalancha de repartidores en lugares de intensa concentración de público (accesos a los transporte público, a centros comerciales, espectáculos, etc.), y la proliferación de ejemplares abandonados por su rápido consumo sin coste para el lector, son algunas de las razones que han movido a los Ayuntamientos a tratar de racionalizar la actividad de distribución de este tipo de publicaciones sin reparar, a veces, en la trascendencia de dicha intervención que condiciona el ejercicio de derechos fundamentales de la comunicación y, en particular, de la tradicionalmente denominada libertad de imprenta.

\subsection{Delimitación del concepto de prensa de distribución gratuita e identificación de las publicaciones así consideradas}

Una vez realizadas las anteriores consideraciones resulta necesario comenzar delimitando qué es lo que se entiende por prensa gratuita, ya que tras esta

\footnotetext{
${ }^{1}$ De hecho, según datos de finales de 2005, el diario de información general más leído fue 20 Minutos, de distribución gratuita que cuenta con unos 2.298 .000 de lectores de media diaria, mientras que el primer diario de pago en número de lectores fue El País que se queda en 2.048.000. Les siguen otros dos diarios gratuitos que son Qué! (1.923.000) y Metro (1.904.000), tras los que se sitúa el diario de pago El Mundo con 1.342.000.

${ }^{2}$ La oferta de publicaciones de distribución gratuita resulta indudablemente superior a los de pago ya que en 2005 supusieron un 19,79 por ciento del total de títulos distribuidos (157 publicaciones distintas), frente a los diarios de pago que se limitaban a 11,23 por ciento (97 diarios).

En cuanto al número de ejemplares distribuidos se aprecia un crecimiento espectacular ya que el número se ha doblado en un solo año pasando de 162.688 .042 en el 2004 a 343.071 .992 en 2005, mientras que la difusión de los diarios de pago se ha estancado en un crecimiento entre 1.451.702.421 en 2004 y 1.477.103.003 en 2005, por lo que de una relación en 2004 de 6,95 por ciento de las publicaciones gratuitas han pasado a ocupar un 13,40 por ciento de los ejemplares distribuidos, mientras que los diarios de pago han disminuido su porcentaje de un 61,98 por ciento en 2004 a un 57,67 por ciento en 2005.

Estos datos se han extraídos de la información proporcionada por Oficina de Justificación de la Difusión (OJD) —división de Información y Control de Publicaciones, S.A. encargada de la realización, verificación de las cifras de difusión de las publicaciones-, a través de su página web http:// www.ojd.es/html/cifras.htm
} 
LA INTERVENCIÓN MUNICIPAL SOBRE LA DISTRIBUCIÓN GRATUITA DE PRENSA...

ambigua expresión de uso común se encuentran diversas actividades que no siempre responden a un mismo concepto y que no se someten a un régimen jurídico común.

En primer lugar, y aunque parezca una redundancia, hemos de señalar que se trata efectivamente de prensa. Dentro de los medios impresos, que abarcan toda reproducción gráfica destinada o que pueda destinarse a ser difundida, la prensa como publicación periódica, se distinguen de las publicaciones unitarias (libros, folletos, hojas sueltas, carteles y otros impresos análogos), por presentar como característica esencial una frecuencia más o menos determinada en su aparición (se trata de diarios, semanarios y publicaciones con una determinada frecuencia).

A partir de esta distinción entre publicaciones periódicas y unitarias, se puede señalar con mayor precisión que la prensa distribuida con carácter gratuito abarca comunicaciones impresas puestas a disposición del público a intervalos regulares de tiempo (por lo general), durante un tiempo indeterminado, bajo el mismo título, en serie continuada y con fecha y numeración correlativa ${ }^{3}$.

Más allá de esta distinción no existen mayores precisiones legales en torno a la naturaleza de la prensa ya que, como se comprobará, no se somete a un régimen jurídico específico sino que su ejercicio es prácticamente libre. Ni siquiera se exige una periodicidad determinada o máxima bastando que tenga un carácter temporal indefinido pues de otro modo constituirían publicaciones unitarias. No obstante, en el caso de las publicaciones distribuidas gratuitamente se considera convencionalmente una periodicidad máxima que reduce el ámbito de las mismas a aquéllas publicadas con periodicidad no superior a un $\mathrm{mes}^{4}$.

Dentro de la caracterización de la prensa se ha de hacer referencia asimismo a su contenido para poder distinguirla de la mera publicidad. En este sentido se entiende que se trata de publicaciones periódicas que tienen contenido redactado de elaboración propia con carácter informativo y de opinión. De este modo se excluyen las publicaciones cuyo contenido sea exclusivamente publicitario ${ }^{5}$. En el caso de la prensa de distribución gratuita, al sostenerse

\footnotetext{
${ }^{3}$ Así se definen las publicaciones periódicas frente a las unitarias en el artículo 10 de la Ley 14/1966 y artículo 3 del Real Decreto 2089/1984, de 14 de noviembre, por el que se desarrolla la Ley 29/1984, de 2 de agosto, por la que se regula la concesión de ayudas a Empresas Periodísticas y Agencias Informativas.

${ }^{4}$ Así lo exige la Asociación Española de Prensa Gratuita en el artículo 2 de sus Estatutos para poder asociarse como empresa editora de publicaciones de distribución gratuita.

${ }^{5}$ Entendiendo por publicidad toda forma de comunicación realizada por una persona física o jurídica, pública o privada, en el ejercicio de una actividad comercial, industrial, artesanal o profesional, con el fin de promover de forma directa o indirecta la contratación de bienes muebles o inmuebles, servicios, derechos y obligaciones, tal y como la define el artículo 1 de la Ley 34/1988, de 11 de noviembre, General de Publicidad.
} 
económicamente a través de la publicidad que contiene, se produce notable disminución del contenido de redacción propia. El problema se plantea en la fijación del límite que separa la prensa de la publicidad en el caso de las publicaciones periódicas ya que no existe al respecto ningún criterio legal más que lo dispuesto en algunas ordenanzas de ordenación de la distribución gratuita de prensa que exigen un contenido "de carácter predominantemente informativo que no sea mera publicidad". A pesar de esta indeterminación, es criterio comúnmente aceptado el límite mínimo de un 30 por ciento de contenido de elaboración propia para considerar que se trata de una publicación periódica y no de mera publicidad ${ }^{6}$.

En este sentido, y por lo que respecta también al contenido, es necesario señalar que, aunque tampoco se deriva de ninguna norma específica, se considera que se trata de un contenido original. Se produce en este punto el mismo dilema en torno a los límites con respecto al alcance del contenido que sea mera reproducción o traducción de textos ajenos para considerar que se trata de una publicación de elaboración propia. Este límite no ha sido fijado legal ni convencionalmente ya que sus consecuencias se trasladan al ámbito privado por lo que respecta a la protección de los derechos de propiedad intelectual.

Por último, del hecho de que se exijan estas dos características, carácter periódico y contenido de naturaleza no mayoritariamente publicitaria de elaboración propia para que una publicación impresa tenga la consideración de prensa, se deriva una cierto carácter profesional en el desarrollo de dicha actividad. Por lo tanto se trata de una actividad desarrollada por empresas periodísticas cuyo objeto es la edición de periódicos impresos por cuenta propia $^{7}$. El carácter empresarial de esta actividad plantea una mayor magnitud e impacto de las publicaciones, lo que motiva precisamente la intervención por parte de los Ayuntamientos que tratan de regular su distribución en la vía pública. No obstante es necesario insistir que tampoco ésta es una exigencia legal específica, por lo que las publicaciones de los partidos políticos, sindicatos, asociaciones de carácter religioso, etc. tienen la consideración de publicaciones periódicas, si bien no suelen ser objeto de la ordenación municipal por no desarrollarse su distribución en la vía pública ni ser ésta de carácter masivo.

En segundo lugar, por lo que se refiere a su distribución, es en ésta donde se encuentra precisamente su elemento de distinción con respecto a las publicaciones de pago. En este sentido es necesario aclarar que más que prensa gratuita, se trata de prensa de distribución gratuita, ya que la naturaleza de la actividad periodística no queda afectada ni condicionada por razón de que la puesta a disposición de la publicación se haga a título oneroso o no. Tanto los diarios de pago como los diarios gratuitos son prensa en sentido on-

\footnotetext{
${ }^{6}$ Así se establece también en el artículo 1 de los Estatutos de la Asociación Española de Prensa Gratuita.
} 
LA INTERVENCIÓN MUNICIPAL SOBRE LA DISTRIBUCIÓN GRATUITA DE PRENSA...

tológico y jurídico, si bien se diferencian por las condiciones de puesta a disposición del público, esto es, si se distribuye mediante contraprestación o no. Incluso desde una perspectiva económica podemos afirmar el error de considerar este tipo de prensa como gratuita, ya que tienen un coste económico que en vez de ser asumido por los destinatarios de la publicación es asumido por los anunciantes dando lugar a una actividad lucrativa.

La distribución de carácter gratuito puede llevarse a cabo principalmente conforme a dos formas básicas:

a) En bloque, que a su vez se desglosa en dos modalidades: la modalidad de ejemplares redistribuidos, de los que solamente se conocen los intermediarios que se comprometen a redistribuir los ejemplares que reciben; en este caso la redistribución se lleva a cabo mediante el reparto individualizado en la vía pública. La segunda modalidad es de ejemplares retirados, que corresponde a aquellos ejemplares depositados en lugares establecidos para que sean retirados voluntariamente por el público; en este caso el depósito tiene lugar en espacios distintos de la vía pública, por lo general, dentro de los accesos de espacios de lugares privados de acceso público como son centros comerciales, salas de espectáculos, etc.

b) Por buzoneo que es la modalidad en la que los ejemplares son depositados en los buzones domiciliarios de los destinatarios, o realizada de forma similar, en una determinada área geográfica.

Al margen de las modalidades incluidas en los apartados anteriores es posible identificar otras como la distribución a través de los quioscos a pesar de la presión de las publicaciones de pago para erradicar este tipo de publicaciones de dichos establecimientos ${ }^{8} \mathrm{o}$ la distribución previa demanda de los interesados, o la puesta a disposición individualizada en medios de transporte como el avión o el tren (Ronda Iberia).

A partir de esta delimitación del concepto de prensa de distribución gratuita es posible llevar a cabo una identificación de las publicaciones que tienen dicha consideración y clasificarlas conforme a los criterios que siguen a continuación ${ }^{9}$ :

\footnotetext{
${ }^{7}$ Así se definen los sujetos que desarrollan esta actividad en el artículo 16 de la Ley 14/1966.

${ }^{8}$ De hecho en la Sentencia de la Audiencia Provincial de Barcelona de 1 de diciembre de 2004 se confirma la sentencia del Juzgado de Primera Instancia que condenó a determinadas editoras de publicaciones de pago al haber sido denunciadas por Metro News, S.L por competencia desleal en tanto presionaban a los quioscos de Barcelona que habían aceptado dinero para distribuir el diario gratuito Metro.

${ }^{9}$ Se sigue en este punto el nomenclator de clasificación por las características, contenido y público lector empleado por la empresa de Información y Control de Publicaciones, S.A. en sus Normas Técnicas de Control de Revistas, tal y como se contienen en la dirección de Internet http://www.ojd.es/html/ reglamentos.htm
} 
a) En función de su ámbito territorial se distinguen publicaciones de carácter nacional, si bien cuentan con ediciones locales (20 minutos, Qué!, Metro, Kinépolis Magazine), o de carácter regional o local (Albacete a Mano, El Distrito Salamanca y Retiro, Tot Badalona).

b) En función de su periodicidad es posible distinguir aquellas publicaciones de carácter diario, que son las editadas con el mismo título cuatro o más días por semana (20 minutos, Qué!, Metro, La Voz del Deporte); las de carácter semanal, que son las publicaciones editadas menos de tres veces por semana; las quincenales, que son publicaciones que se editan cada quincena o también dos o tres veces al mes (MediaPunta); las mensuales, que se editan cada mes (Cinerama, Estrenos de Video), y otras publicaciones que se editan con periodicidad superior a la mensual (bimestral, trimestral, cuatrimestral, semestral, anual, etc.) que no se sitúan dentro del núcleo principal de las publicaciones de distribución gratuita por ser menos relevantes a efectos de su distribución.

c) Con respecto a su contenido varía desde aquellos de contenido de información y opinión general (20 minutos, Qué!, Metro) o de interés temático, entre los que se distinguen los de cine, teatro y video (Cinebank, Cinerama, Kinépolis Magazine), las deportivas y de ocio (La Voz del Deporte, MediaPunta, Andalucía Costa del Golf), las de economía, empresas y negocios (Money Market), las dirigidas a inmigrantes (Latino, Sí Se Puede), las de estilo de vida (Freestyle, Oxigenol), las de peluquería, perfumería y cosmética, las familiares (Todopapa, Guía Práctica del Embarazo), las de farmacia (El Periódico de la Farmacia), las femeninas, (De Corazón, Wapa Magazine), gastronómicas (Mivino), de hogar y entretenimiento (Imagínate), infantiles, de Internet y telecomunicaciones (Comunícate), las inmobiliarias (Real State Moraleja, Selecció Inmobiliaria Barcelona), las de literatura, cultura y pensamiento (Selecció Literaria), las de marketing promocional (Family Check), las de medio ambiente, motor (Motor 8+), musicales (Variaciones), educación y enseñanza (Gaceta Universitaria), reclamos publicitarios, turismo y hostelería (Bienvenidos a Mallorca, Check In Sol Meliá), viajes (Paisajes desde el Tren, Ronda Iberia), videojuegos (Gamers Magacine). También, con respecto a su contenido, es posible distinguir publicaciones de distribución gratuita de carácter técnico y profesional, entre las que se distinguen las de ganadería y pesca, arquitectura y construcción, comercio, economía, empresa y negocios, estética, cosmética, peluquería y perfumería, farmacia, las de información, Internet y telecomunicaciones, medicina, educación y enseñanza, tecnología industrial intersectorial, transporte, logística y distribución. 
LA INTERVENCIÓN MUNICIPAL SOBRE LA DISTRIBUCIÓN GRATUITA DE PRENSA...

\subsection{Descripción del régimen jurídico de la prensa de distribución gratuita}

La prensa de distribución gratuita se encuentra sometida al régimen jurídico común de los medios impresos periódicos. Como es sabido, los medios impresos permanecen en la actualidad en una cierta anomia intencionada que permite el libre ejercicio de los derechos de la comunicación, si bien existe una mínima intervención destinada a asegurar un cierto orden, así como para garantizar las condiciones de su ejercicio.

Efectivamente, tras la aprobación de la Constitución de 1978 se produjo una derogación parcial de la Ley 14/1966, de 18 de marzo, de Prensa e Imprenta. Esta Ley preconstitucional, como norma de cabecera del régimen jurídico de la libertad de imprenta supuso una relativa liberalización del régimen de los medios impresos imperante hasta ese momento ya que eliminó el régimen de censura previa. Su derogación se especificó en el Real Decreto-Ley 24/1977, de 1 de abril, sobre libertad de expresión, que restableció la libertad de expresión y por la Ley 29/1984, de 2 de agosto, por la que se regula la concesión de ayudas a Empresas periodísticas y agencias informativas, así como por la inconstitucionalidad de determinados artículos declarada por el Tribunal Constitucional en diversas sentencias ${ }^{10}$.

El régimen jurídico general de los medios impresos actualmente vigente sólo introduce como limitaciones algunas relativas a las participaciones extranjeras en las empresas de comunicaciones. Por lo demás, como trámite para el ejercicio de la actividad no existe ninguna otra restricción, ya que la inscripción en el Registro de Empresas Periodísticas establecido por el Real Decreto 2089/1984 es de carácter voluntario.

Entre las obligaciones de carácter mínimo figura la exigencia del pie de imprenta, conforme al artículo 11 de la Ley 14/1966, que es la constancia del lugar y año de la impresión, así como el nombre y el domicilio del impresor, así como el día, el mes, el nombre y apellidos del Director, el domicilio y razón social de la Empresa periodística y la dirección de sus oficinas, redacción y talleres.

Por otra parte, existe una obligación de facilitar ejemplares de cada número al correspondiente Depósito Legal, al igual que todo el resto de publicaciones, reproducidas en cualquier soporte (libros, folletos, hojas, carteles, periódicos, revistas, mapas, partituras, vídeos analógicos, $\mathrm{CD}$ audio, disquetes, CD-ROM, DVD-ROM, etc.), por cualquier procedimiento para distribución pública, alquiler o venta.

10 Vallés Copeiro del Villar, Antonio: Curso de Derecho de la Comunicación Social, Tirant lo Blanch, Valencia, 2005, p. 342. 
No se trata de un requisito previo a la publicación, ya que la publicación no se encuentra sometida a limitación o restricción alguna, sino de una obligación derivada de la voluntad de los poderes públicos de recopilar y preservar colecciones de materiales bibliográficos de todo tipo, de redactar y publicar la bibliografía nacional, el control estadístico de la producción editorial y la constitución de colecciones bibliográficas regionales o locales ${ }^{11}$.

En cuanto a su distribución y reparto, al igual que en el caso de la prensa de pago, se trata de una actividad desarrollada por profesionales especializados que no está sometida a una intervención pública específica en cuanto tal. Sin embargo, en la medida que la distribución y reparto se lleve a cabo en la vía pública esta actividad será objeto de la intervención de los Ayuntamientos ya que se desarrolla en el dominio público de titularidad municipal, que se analizará con profundidad más adelante.

El seguimiento de esta actividad permite determinar el impacto efectivo de cada publicación en función del número de ejemplares distribuidos y vendidos o repartidos, lo que ha motivado su control para obtener y gestionar esta información que resulta fundamental para los propios medios que adaptan sus estrategias a los resultados de su impacto comunicativo, para las agencias publicitarias que diseñan sus campañas publicitarias conforme a los mismos, y para los propios anunciantes que deciden así cuáles son los medios más idóneos para sus campañas.

Dicho seguimiento constituye un derecho de los anunciantes (artículo 12 Ley 34/1988, de 11 de noviembre, General de Publicidad), y es de carácter voluntario. Este se ejerce a través de sociedades mercantiles de composición corporativa en las que participan representantes de empresas del sector (editoras, distribuidoras y de publicidad), así como asociaciones de editores y de anunciantes.

La empresa de esta índole más conocida y que desarrolla dicha actividad con carácter casi exclusivo lo que plantea problemas por su posible carácter contrario a la libre competencia ${ }^{12}$ es Información y Control de Publicaciones, S.A. cuyo objetivo ${ }^{13}$ es obtener y facilitar información útil y puntual

\footnotetext{
${ }^{11}$ Esta obligación se deriva de las Órdenes del Ministerio de Educación y Ciencia de 30 de octubre de 1971 y de 20 de febrero de 1973, que constituye la regulación a nivel estatal, si bien en numerosas CCAA se han asumido competencias al respecto desarrollándose esta legislación básica estatal ordenando los depósitos legales a nivel autonómico. La Biblioteca Nacional, así como las otras bibliotecas depositarias (bibliotecas públicas del Estado y bibliotecas autonómicas), reciben los materiales bibliográficos que se depositan en las 55 oficinas que gestionan el Depósito Legal.
}

${ }^{12}$ En una Resolución de 16 de febrero de 2005, el Tribunal de Defensa de la Competencia dictó la Resolución 576/04, Multiprensa, por la que declara que las decisiones adoptadas por OJD y AIMC en relación con la suspensión de la emisión de la Acreditación de Distribución y Tirada de los Diarios 20 Minutos editados por Multiprensa, no constituye una práctica contraria a la competencia. No obstante dicha Resolución, que contenía dos votos particulares, no es firme por lo que se mantiene la polémica al respecto.

${ }^{13}$ Tal y como se señala en su página web http://www.ojd.es/html/home.htm 
LA INTERVENCIÓN MUNICIPAL SOBRE LA DISTRIBUCIÓN GRATUITA DE PRENSA...

de la difusión y distribución de las publicaciones periódicas y del tráfico en internet para uso de anunciantes, agencias de publicidad, editores y demás personas o entes interesados.

Dentro de Información y Control de Publicaciones destaca su división Oficina de Justificación de la Difusión (OJD) ya que es la encargada de la realización, verificación de las cifras de difusión de las publicaciones cuyos ejemplares son vendidos a terceros a través de los distintos canales, así como de las cifras de difusión de las publicaciones cuyos ejemplares son enviados o entregados de forma gratuita mediante envíos personalizados.

La importancia y especificidad de la prensa de distribución gratuita motivó la constitución de otra división dentro de la empresa que es la de $\mathrm{Pu}$ blicaciones Gratuitas Ejemplares Distribuibles (PGD) encargada de ejecución y emisión de Acreditaciones de Control de publicaciones que se distribuyan de forma gratuita de las cuales únicamente se pueden verificar los ejemplares entregados a distribución.

Por último, aunque no tenga que ver directamente con el régimen jurídico, resulta relevante señalar que las empresas editoras de publicaciones de distribución gratuita se integran en una organización de carácter corporativo, que es la Asociación Española de la Prensa Gratuita, creada en febrero del 2001 y que acoge y representa a todas las editoriales y publicaciones de prensa gratuita para constituirse en interlocutor válido de este colectivo ${ }^{14}$. Además de la defensa de sus intereses, desarrolla una actividad de autorregulación de la actividad de sus asociados mediante la redacción de Códigos Deontológicos para autocontrol de las posibles irregularidades en el desarrollo de su actividad.

\section{FUNDAMENTO Y ANÁLISIS DEL RÉGIMEN JURÍDICO DE LA INTERVENCIÓN MUNICIPAL SOBRE LA ACTIVIDAD DE DISTRIBUCIÓN GRATUITA DE PRENSA}

\subsection{Fundamento y descripción del régimen jurídico de la intervención municipal sobre la distribución gratuita de prensa en la vía pública}

Si bien la actividad de distribución y reparto de prensa no se encuentra sometida a ningún tipo de intervención pública específica que ordene direc-

\footnotetext{
${ }^{14}$ Esta es la presentación que hace de sí misma la Asociación Española de la Prensa Gratuita en su página web http://www.prensagratuita.org La AEPG cuenta entre sus asociados con las principales editoriales de Prensa Gratuita del país. Son 92 publicaciones distribuidas de la siguiente forma: Andalucía 12, Aragón 2, Castilla-La Mancha 3, Castilla y León 2, Cataluña 38, Comunidad de Madrid 16, Comunidad Valenciana 9, Galicia 1, Illes Balears 6, Islas Canarias 1 y Región de Murcia 1. Si bien los datos no son completos, las publicaciones pertenecientes a la Asociación Española de Prensa Gratuita suman un total de 9 millones de ejemplares y una audiencia de 23 millones de lectores.
} 
tamente la forma de ejercicio del derecho fundamental de la comunicación, sin embargo, en la medida que la distribución y reparto de los ejemplares se desarrolla principalmente en la vía pública y afecta a intereses municipales es objeto de la intervención por parte de los Ayuntamientos.

Como es bien sabido, las entidades locales carecen de competencia alguna tanto para desarrollar el régimen del ejercicio de los derechos fundamentales como para limitar dicho ejercicio en tanto existe al respecto una reserva de ley (art. 53.1 CE), lo cual no impide que con su intervención sobre el uso del dominio público municipal puedan afectar incidentalmente a dicho ejercicio condicionándolo siempre que se dirija específicamente a los aspectos que son propios de su competencia, que no afecte al contenido esencial de los derechos y que cuente con la cobertura de una norma con rango de Ley.

Efectivamente, la distribución y reparto de prensa, sea mediante pago o con carácter gratuito, es una actividad privada que puede ser sometida a intervención municipal por diversas razones que la justifican y en base a los títulos competenciales que se les reconoce a los Ayuntamientos, entre los que destaca la gestión de su dominio público viario.

En primer lugar, hemos de recordar que en cuanto actividad de finalidad pública, la distribución y reparto de prensa en general sea o no en la vía pública o con carácter gratuito u oneroso, puede ser intervenida desde el ámbito municipal en el ejercicio de la función de policía en pro del buen orden público y ciudadano, tal y como se les reconoce en el artículo 1 del Decreto de 17 de junio de 1958 de Servicios de las Corporaciones Locales (RSCL). No obstante este título indeterminado exige que la perturbación o la amenaza del mismo sea grave, y que exista motivación y necesidad cualificada de la intervención pública, además de tener que equilibrarse con el principio pro libertate que exige la elección del medio menos restrictivo para la libertad individual (artículos 3, 4 y 6 RSCL).

Estas condiciones especialmente exigentes parecen excluir a la distribución y reparto de prensa de la intervención municipal de policía. No obstante, y en tanto se trata de una actividad que presenta un componente económico, sea en la distribución mediante pago o en la gratuita, podría ser sometida a la intervención municipal que los Ayuntamientos despliegan sobre el resto de actividades económicas que se desarrollan dentro de los municipios.

En segundo lugar, y siempre dentro de este título relativo a la tranquilidad, seguridad, salubridad ciudadanas, se encajaría también la posible intervención sobre la distribución y reparto de prensa en tanto esta actividad tiene un impacto especialmente relevante en lo que se refiere a la limpieza y decoro del municipio, en especial por lo que se refiere a la distribución de carácter gratuito. 
LA INTERVENCIÓN MUNICIPAL SOBRE LA DISTRIBUCIÓN GRATUITA DE PRENSA...

Efectivamente la tranquilidad pública y la pacífica convivencia, así como la limpieza y el control de los posibles restos de la venta y/o distribución masiva de ejemplares impresos permitirían llevar a cabo una ordenación del desarrollo de estas actividades a través de ordenanzas específicos sobre distribución de prensa, o bien sobre limpieza urbana u ordenanza de civismo. En este sentido cabría incluso que la intervención municipal se extendiese tanto a la distribución gratuita como onerosa de prensa, abarcando espacios de titularidad pública o privada.

Por último, podemos identificar el fundamento más relevante sobre el que se sostiene la intervención municipal sobre la distribución y reparto de prensa que, en este caso, se circunscribe a la actividad desarrollada en vías y espacios públicos. En tanto esta actividad suele desarrollarse en vías públicas y otros espacios de dominio y uso público de titularidad municipal, los Ayuntamientos cuentan con capacidad de intervenir sobre los usos que se pretenda hacer de los mismos estableciendo una regulación específica dirigida a garantizar un uso adecuado y racional en garantía del interés público local manifestado en el libre tránsito peatonal.

El régimen jurídico de estos bienes de dominio público local viene dado por la siguiente normativa, cuya aplicación resulta un tanto compleja ya que se entrecruzan normas generales de patrimonio público y especiales de bienes de las entidades locales, tanto de carácter estatal como autonómico y local ${ }^{15}$ :

a) Normativa general sobre patrimonio de las Administraciones Públicas, que se contiene con carácter básico en la Ley 33/2003, de 3 de noviembre, de Patrimonio de las Administraciones Públicas (LPAP).

b) Normativa especial sobre bienes de las Entidades Locales, en la que debe distinguirse la legislación básica estatal sobre bienes locales contenida en los artículos 79 a 83 de la Ley 7/1985, de 2 de abril, de Bases del Régimen Local (LBRL) y los artículos 74 a 87 del Real Decreto Legislativo 781/1986, de 18 de abril, por el que se aprueba el Texto Refundido de las disposiciones legales vigentes en materia de Régimen Local (TRRL).

Esta normativa básica es desarrollada por la respectivas Comunidades Autónomas que aprueban normas sobre régimen local, que si bien no introducen variaciones entre el régimen del dominio público local sí completan su régimen jurídico ${ }^{16}$.

\footnotetext{
${ }^{15}$ Este esquema del régimen jurídico de los bienes de las Entidades Locales se deduce de la Sentencia del Tribunal Constitucional 214/1989, y viene definido en el artículo 1 RBCL.

${ }^{16}$ Así, el Decreto 336/1988, de 17 de octubre de la Generalidad de Cataluña, por el que se aprueba el Reglamento de Patrimonio de los Entes Locales, la Ley 7/1999, de 29 de septiembre, de Bienes de las Entidades Locales de Andalucía; el Decreto Foral 280/19990, de 18 de octubre, por el que se aprueba el Reglamento de Bienes de las Entidades Locales de Navarra.
} 
Con carácter supletorio, conforme al art. 149.3 CE, se aplica asimismo el Real Decreto 1372/1986, de 13 de junio, Reglamento de Bienes de las Corporaciones Locales (RBCL), que es la norma de aplicación preferente en las Comunidades Autónomas que no hayan dictado normas sobre bienes de las Entidades Locales.

c) Por último, y para completar el marco jurídico de la distribución de prensa en la vía pública, se ha de tener en cuenta que cada Ayuntamiento puede dictar reglamentos para ordenar la utilización de estos bienes, dentro de lo dispuesto por el Estado y por la Comunidad Autónoma correspondiente, a través de sus respectivas ordenanzas municipales.

Conforme a este régimen de los bienes de las Entidades Locales podemos constatar que la actividad de distribución y reparto gratuito de prensa se desarrolla principalmente en bienes de dominio público local. Efectivamente, las vías y otros espacios públicos son calificados como bienes de dominio público conforme a los artículos 74 TRRL y 3 RBCL ${ }^{17}$, que son precisamente los espacios donde se lleva a cabo la distribución y reparto de prensa por lo general.

Las condiciones generales para el disfrute y aprovechamiento del dominio público vial, así como del resto de bienes de dominio público, se determinan en el Capítulo I sobre la Utilización de Bienes y Derecho de Dominio Público de la LPAP, completado con lo dispuesto por el RBCL. A partir de la exigencia de autorización por parte de la autoridad competente para ocupar los bienes de dominio público (art. 84 LPAP), se establecen los distintos tipos de uso (art. 85 LPAP) distinguiendo entre:

a) Uso común, que es el que corresponde por igual y de forma indistinta a todos los ciudadanos, de modo que el uso por unos no impide el de los demás interesados;

b) Uso común especial, que es el que, sin impedir el uso común, supone la concurrencia de circunstancias tales como la peligrosidad o intensidad del mismo, preferencia en casos de escasez, la obtención de una rentabilidad singular u otras semejantes, que determinan un exceso de utilización sobre el uso que corresponde a todos o un menoscabo de éste;

c) Uso privativo que determina la ocupación de una porción del dominio público, de modo que se limita o excluye la utilización del mismo por otros interesados.

\footnotetext{
${ }^{17}$ A partir del reconocimiento por el artículo 79 LBRL de la posibilidad de que las Entidades Locales cuenten con bienes de su titularidad, que pueden ser de dominio público o patrimoniales, entre los primeros se cuentan los caminos y carreteras, plazas, calles, paseos, parques, aguas de fuentes y estanques, canales, puentes y demás obras públicas de aprovechamiento o utilización generales cuya conservación y policía sean de la competencia de la Entidad Local conforme al artículo 74 TRRL y al artículo 3 RBCL.
} 
LA INTERVENCIÓN MUNICIPAL SOBRE LA DISTRIBUCIÓN GRATUITA DE PRENSA...

A esta clasificación, que ya se contenía en el artículo $74 \mathrm{RBCL}{ }^{18}$, se añade la distinción que este mismo dispone entre uso normal, cuando fuere conforme con el destino principal del dominio público a que afecte, y un uso anormal, si no fuere conforme con dicho destino.

La clasificación de la actividad de distribución de prensa dentro de uno de estos tipos de uso depende del tipo de distribución de que se trate, aunque no siempre resulta unívoca la correspondencia entre cada tipo de distribución y los usos. En este punto es necesario recordar que se trata de la distribución de prensa llevada a cabo en el dominio público viario en general, con independencia de si se hace con carácter gratuito u oneroso, ya que la diferencia entre una y otra calificación depende de la intensidad en la utilización que se haga del dominio público, sin que resulte especialmente relevante que se haga o no con carácter gratuito.

Cuando la distribución de prensa en la vía pública se lleva a cabo mediante instalaciones de carácter permanente que ocupan el dominio público, es decir, los tradicionales quioscos u otro tipo de construcciones no desmontables, no cabe duda de que el desarrollo en dichas condiciones supone un uso privativo normal en tanto excluye la utilización por otros interesados. Esta actividad estará sujeta a concesión administrativa que se otorga previa licitación y adjudicación por concurso, por un tiempo definido y bajo unas condiciones especificadas por el propio Ayuntamiento en las ordenanzas reguladoras de estos supuestos de ocupación permanente del dominio público y en la propia concesión (arts.78-90 RBCL).

En el caso de que la distribución y reparto se lleve a cabo mediante instalaciones desmontables o directamente por repartidores a las personas que se encuentren en la vía pública o bien mediante depósito de los ejemplares en la misma (lo que generalmente está prohibido por las Ordenanzas Municipales), se consideran actividades de uso del dominio público calificables en todo caso como de uso común, ya que no impide el de los demás interesados.

No obstante, las dificultades surgen al concretar si se trata de un uso común general o especial. En este sentido es necesario entrar a distinguir las características específicas en las que se lleve a cabo la distribución y/o el reparto, ya que dentro del uso común se incluiría desde el reparto de dos o más personas en un mismo punto con un carrito o elemento equivalente que se instala para depositar los ejemplares objeto del reparto hasta el reparto por parte de una sola persona con carácter esporádico sin accesorio alguno. Si

\footnotetext{
${ }^{18}$ Efectivamente el artículo 74 RBCL ya calificaba los distintos usos de los bienes de dominio público local en uso común, que es el correspondiente por igual a todos los ciudadanos indistintamente, de modo que el uso de unos no impida el de los demás interesados, y que, a su vez se distingue en uso común general, cuando no concurran circunstancias singulares, y uso común especial, si concurrieran circunstancias de este carácter por la peligrosidad, intensidad del uso o cualquiera otra semejante. Frente al uso común, el uso privativo, se distingue por ser el constituido por la ocupación de una porción del dominio público, de modo que limite o excluya la utilización por los demás interesados.
} 
bien es posible que por la escasa periodicidad, la reducida tirada y la técnica de distribución a mano pudiera motivar la calificación de uso común general, no cabe duda de que el carácter diario de muchas de las publicaciones, la presencia simultánea de diversos repartidores, la utilización de accesorios para facilitar el reparto y el carácter masivo del mismo, conducen a calificar esta actividad como uso común especial por la intensidad en el uso del dominio público vial.

Esta clasificación resulta fundamental ya que los títulos habilitantes y el régimen jurídico son distintos para cada uno de los diversos tipos de uso (art. 86 LPAP). En el caso del uso común éste podrá realizarse libremente, sin más limitaciones que las derivadas de su naturaleza, lo establecido en los actos de afectación o adscripción, y en las disposiciones que sean de aplicación; en el caso del uso común especial y en el del uso privativo mediante ocupación con instalaciones desmontables o bienes muebles, estarán sujetos a autorización o, si la duración del aprovechamiento o uso excede de cuatro años, a concesión; por último, en el caso del uso privativo de los bienes de dominio público que determine su ocupación con obras o instalaciones fijas deberá estar amparado por la correspondiente concesión administrativa.

De forma paralela discurren las exigencias con respecto a los títulos habilitantes aplicables a los bienes de dominio público local, ya que el art. 76 RBCL establece que el uso común general de los bienes de dominio público se ejerce libremente, con arreglo a la naturaleza de los mismos, a los actos de afectación y apertura al uso público y el ordenamiento jurídico en general (art. 76 RBCL), mientras que el uso común especial normal se encuentra sujeto a licencia, ajustada a la naturaleza del dominio, a los actos de su afectación y apertura al uso público y a los preceptos de carácter general (art. 77 RBCL). En este ultimo caso las licencias se otorgan directamente, salvo si por cualquier circunstancia se limitare el número de las mismas, en cuyo caso lo serán por licitación y, si no fuere posible, porque todos los autorizados hubieren de reunir las mismas condiciones, mediante sorteo (art. 77.2 RBCL). Asimismo es necesario tener en cuenta que estas licencias no son transmisibles cuando se refieran a las cualidades personales del sujeto o cuyo número estuviere limitado, y las demás, lo serán o no según se previera en las ordenanzas (art. 77.3 RBCL).

Asimismo se ha de tener en cuenta que, en el caso de que se considere un uso común especial, la habilitación a los Ayuntamientos para ordenar dichas actividades alcanzará una especial intensidad en tanto se les reconoce capacidad para intervenir sobre la actividad de los ciudadanos en los servicios de particulares destinados al público mediante la utilización especial o privativa de bienes de dominio público, para imponer la prestación de aquéllos debidamente y bajo tarifa (art. 1.4 RSCL).

En cualquier caso, son los propios Ayuntamientos los que llevan a cabo la calificación de las distintas actividades de distribución de prensa como de 
LA INTERVENCIÓN MUNICIPAL SOBRE LA DISTRIBUCIÓN GRATUITA DE PRENSA...

uso común general o especial, ya lo hagan con carácter general en sus ordenanzas municipales, o bien sea mediante actos singulares frente a las solicitudes para el desarrollo de la misma o ante la toma de conocimiento de la existencia de dicha actividad.

En este sentido es necesario señalar que existen discrepancias con respecto a la calificación que de la actividad de distribución de prensa llevan a cabo uno y otros Ayuntamientos. Así, en el caso de Barcelona se puede apreciar que mediante Ordenanza se califica esta actividad como un uso común general del dominio público, mientras que en otros municipios (en la mayoría) se califican como uso común especial (Zaragoza, Valencia, Sevilla).

\subsection{Distinción de la intervención municipal sobre otras actividades distintas a la distribución gratuita de prensa en la vía pública}

La delimitación del concepto de prensa de distribución gratuita nos permite distinguir la intervención municipal que se desarrolla sobre otras actividades similares que constituyen el objeto de ordenanzas municipales específicas que, por lo tanto, no le resultan de aplicación.

En primer lugar, en tanto se trata de la distribución gratuita de prensa, hemos de señalar que se trata de publicaciones de carácter periódico y, en cierta medida, profesional, por lo que no se incluiría en el objeto de la intervención municipal específico sobre la distribución de prensa, la distribución de otras publicaciones de carácter no periódico y con carácter no profesional. En estos casos, si bien se lleva a cabo el ejercicio del derecho fundamental a libertad de expresión, no tendría toda la plenitud propia de los derechos de comunicación que se reconoce especialmente a los medios de comunicación social entre los que se cuenta la prensa tanto por su carácter periódico y por el volumen de su tirada, que permite identificar un público propio y específico. No se suele incluir estas actividades en la ordenación específica municipal de la distribución gratuita de prensa ni existe una regulación específica para la misma - aunque en ocasiones de reconduce a la actividad publicitaria-, ya que se trata de supuestos que no merecen una especial atención por parte de los municipios por su menor relevancia (distribución de octavillas, panfletos, incluso la reciente actividad de bookcrossing). En su caso estas actividades estarían simplemente sometidas a la normativa municipal sobre limpieza y conservación del medio ambiente urbano.

En segundo lugar es necesario distinguir la distribución gratuita de prensa de la distribución de publicidad. Si bien ésta tiene un gran contenido publicitario al ser su principal fuente de financiación, esto no la convierte en simples impresos publicitarios. Esta distinción resulta especialmente importante a la hora de considerar el régimen jurídico que le resulta aplicable a su 
distribución ya que, en este caso existe una regulación específica de la publicidad tanto a nivel autonómico ${ }^{19}$ como municipal ${ }^{20}$. El objeto de esta normativa es ordenar la difusión de mensajes publicitarios a través de sus distintas modalidades, como son la publicidad estática (carteles, vallas publicitarias y pancartas), publicidad móvil (coches publicitarios, publicidad aérea) y la publicidad impresa que se basa en el reparto de impresos en la vía pública de forma individualizada (manual o automática) o mediante su puesta a disposición.

Esta última modalidad podría llegar a confundirse con la distribución de la prensa gratuita por la importancia que la publicidad tiene en el contenido de estas últimas y por la similitud de la técnica de puesta a disposición ya que en ambos casos se trata de un reparto en la vía pública con carácter gratuito.

Sin embargo, la distribución de prensa gratuita y el reparto de publicidad difieren por razón del objeto de una y otra, ya que en un caso se trata de la comunicación de información y opinión en el ejercicio del derecho fundamental de la comunicación, mientras que en el otro caso sería de meros mensajes publicitarios sometidos a la normativa estatal (LGP) y autonómica y local referida. No obstante, a nivel municipal esta distinción no resulta tan clara, ya que, en el caso de determinados municipios, se lleva a cabo una definición excesivamente amplia del concepto de publicidad ${ }^{21}$, e incluso se produce la asimilación de determinados supuestos de reparto de prensa - como es el caso del buzoneo- a la actividad publicitaria ${ }^{22}$.

Por último, dentro de la actividad de distribución de prensa en la vía pública se lleva cabo a nivel municipal una distinción en función de si se lleva a cabo con carácter gratuito o mediante contraprestación. Si bien hemos señalado que, en ambos casos, se trata de una actividad con un inequívoco trasfondo comercial algunas ordenanzas municipales que regulan actividades comerciales en la vía pública introducen un tratamiento diferenciado.

La venta de prensa en la vía pública se sometería, en este caso, a un régimen jurídico común para las actividades comerciales desarrolladas en el

\footnotetext{
${ }^{19}$ En el caso de las Illes Balears con la Ley 5/1997, de 8 de julio, por la que se regula la publicidad dinámica en las Islas Baleares, y en el caso de Cataluña con la Ley 9/2000, de 7 de julio, de Regulación de la publicidad dinámica en Cataluña.

${ }^{20}$ Como la Ordenanza Municipal sobre Publicidad del Ayuntamiento de Valencia aprobada por Acuerdo de 28 de junio de 1996 (BOP 24 de julio de 1996).

${ }^{21}$ El artículo 12 de la Ordenanza Municipal sobre Publicidad del Ayuntamiento de Valencia aprobada por Acuerdo de 28 de junio de 1996 (BOP 24 de julio de 1996), que define como actividad publicitaria toda acción encaminada a difundir entre el público el conocimiento de la existencia de un actividad política, sindical, asistencial, religiosa, cultural, profesional, deportiva, económica o de productos y servicios o cualquier otra dirigida a recabar la atención del público hacia un fin determinado.

22 En la disposición adicional de la Ordenanza de Zaragoza se asimila a la publicidad la distribución gratuita de prensa mediante su depósito en los buzones, aplicándose a esta actividad lo dispuesto en la correspondiente Ordenanza de actividades publicitarias de ámbito urbano.
} 
LA INTERVENCIÓN MUNICIPAL SOBRE LA DISTRIBUCIÓN GRATUITA DE PRENSA...

municipio. En la medida que se trata de actividades desarrolladas en el dominio público municipal, algunos municipios prevén un régimen jurídico específico que abarca toda la venta ambulante, en el que podrían quedar incluidos ${ }^{23}$. No obstante si la venta se desarrolla en quioscos u otro tipo de estructuras fijas, se suelen establecer una normativa o algunas previsiones específicas en tanto supone un uso intensivo que exige el previo otorgamiento de licencias.

\subsection{Sistematización de la regulación municipal existente de la distribución gratuita de prensa en la vía pública}

El régimen jurídico de la distribución gratuita de prensa se completa con lo dispuesto en los diferentes municipios con respecto al desarrollo de esta actividad en su término municipal. Mediante el ejercicio de su potestad reglamentaria los Ayuntamientos aprueban ordenanzas municipales que, o bien regulan específicamente esta actividad, o bien se incluyen en la regulación general de las actividades, instalaciones y ocupaciones de la vía pública, o no disponen nada al respecto.

\section{a) Ayuntamientos que disponen de una regulación específica de la distribución de prensa gratuita}

En determinados municipios se han aprobado ordenanzas municipales específicas cuyo objeto se centra exclusivamente en la regulación de la actividad de distribución gratuita de prensa en la vía pública, como es el caso de Zaragoza en el que, por Acuerdo del Pleno de 28 de enero de 2004, se aprobó la Ordenanza reguladora de la distribución gratuita de prensa en la vía pública (BOP Zaragoza, de 8 de marzo de 2004, núm. 54).

En el municipio de Sevilla, se aprobó mediante Acuerdo del Pleno de 18 de marzo de 2004, la Ordenanza Reguladora de la Distribución Gratuita de Prensa en los Espacios Públicos del Municipio de Sevilla (BOP Sevilla, de 26 de mayo de 2004, núm. 120), que, igualmente, se centra de forma específica en la regulación de la actividad consistente en la distribución gratuita en la vía pública de prensa, que junto a la información contenga anuncios publicitarios, sin el empleo de instalación permanente alguna.

Asimismo el Pleno del Ayuntamiento de Málaga, aprobó el 28 de abril de 2005, la Ordenanza Reguladora de la Distribución Gratuita de Prensa en la

\footnotetext{
${ }^{23}$ Se trata de Ordenanzas que establecen un régimen de licencia común para todas las actividades comerciales desarrolladas en la vía pública por el uso común especial normal del dominio público con la utilización de puestos temporales de venta (helados, castañas, frutas y caramelos, libros y revistas, flores, fotógrafos).
} 
Vía Pública (BOP Málaga, de 24 de octubre de 2005, núm. 202), con un objeto, estructura y contenido muy similar a las anteriores.

A diferencia de las anteriores, en el municipio de Madrid, mediante Acuerdo del Pleno de 22 de diciembre de 2005 se aprobó la Ordenanza Reguladora de la Venta y Distribución en la Vía Pública de Periódicos, Revistas y Publicaciones (BOCM, de 13 de enero de 2006, núm. 55), en la que se regula la puesta a disposición de publicaciones periódicas tanto con carácter oneroso como gratuito en la vía pública tanto mediante instalaciones fijas (quioscos) como mediante instalaciones móviles.

En otros casos, la ordenación de la actividad de distribución de prensa gratuita se incorpora en el contenido de ordenanzas reguladoras de actividades, instalaciones y ocupaciones de las vías públicas, dentro de las cuales se refieren específicamente a aquella. Así es el caso de la Disposición Adicional Sexta de la Ordenanza reguladora de actividades, instalaciones y ocupaciones en la vía pública de Valencia, introducida en la última modificación de dicha Ordenanza (BOP Valencia, de 30 de enero de 2006).

\section{b) Ayuntamientos que disponen de una regulación genérica de las actividades y ocupación de sus vías públicas}

Al margen de los escasos municipios en los que se ha aprobado una norma específica reguladora de la actividad de distribución gratuita de prensa, en la mayoría de ellos existe una regulación genérica de las actividades desarrolladas en sus vías públicas y espacios públicos, así como las instalaciones u ocupaciones de los mismos.

Se trata de ordenanzas municipales que si bien no se refieren específicamente a la distribución de prensa en la vía pública, son de aplicación a dicha actividad en la medida que se incluye en su ámbito de aplicación.

Es el caso del municipio de Barcelona y su Ordenanza sobre los usos de las vías y los espacios públicos de Barcelona, aprobada por Acuerdo del Consejo Plenario de 27 de noviembre de 1998 (BOP Barcelona de 15 de enero de 1999, núm. 13). Su objeto alcanza a los usos y las actividades que lleven a cabo en las vías y los espacios destinados al uso público, por lo que abarca desde el simple paseo a la instalación de estructuras permanentes como quioscos. Excepcionalmente en el régimen de este tipo de actividades y en la línea de su voluntad de intervención mínima, califica de uso común general el ejercicio de profesión o actividad en la vía pública, por lo que no se somete a licencia previa siempre que, por su naturaleza, no comporte un uso intensivo del espacio público y no afecte a otros usos (artículo 8.2).

No obstante, no son demasiados los municipios que llevan a cabo una regulación unitaria de los usos de su dominio público. Por el contrario, re- 
LA INTERVENCIÓN MUNICIPAL SOBRE LA DISTRIBUCIÓN GRATUITA DE PRENSA...

sulta muy común la fragmentación en la regulación de la utilización del dominio público en función de la actividad de que se trate, dictándose ordenanzas específicas sobre la venta ambulante de alimentos (desde venta de castañas, a helados, etc.) o de objetos (artesanía, souvenir), ordenanzas sobre instalaciones de carácter desmontable (terrazas y veladores de establecimientos dedicados a la hostelería), sobre instalaciones de carácter permanente (sobre la instalación de quioscos de prensa y revistas, del cupón pro-ciegos, o de venta de flores y semillas, o de instalación de contenedores). De este modo resulta frecuente que la actividad de distribución gratuita de prensa en la vía pública no encaje en el objeto de ninguna de estas ordenanzas específicas ni se disponga en ellas un título genérico de intervención, por lo que quedarían sin cobertura normativa local alguna.

\section{c) Ayuntamientos que carecen de regulación alguna de las actividades y ocupaciones de sus vías públicas}

Son mayoría los municipios en los que no se ha aprobado una ordenanza específica reguladora de la actividad de distribución gratuita de prensa, así como aquéllos en los que si bien se han aprobado reglamentos sobre los usos, las instalaciones u ocupaciones de las vías y espacios públicos se ha llevado a cabo de manera fragmentaria (ordenando supuestos específicos sobre la instalación de contenedores, de quioscos, etc.), por lo que dicha actividad permanecería sometida únicamente a lo dispuesto por la normativa estatal y autonómica (en su caso) sobre régimen local, y, en particular, sobre bienes de las corporaciones locales.

En este sentido hemos de recordar que la ausencia de regulación municipal no significa que la distribución gratuita de prensa pueda llevarse a cabo de forma libre, sino que, en cuanto se encuentra sometida a lo dispuesto en la normativa estatal y en la autonómica, es necesario la obtención de licencia municipal (art. $71 \mathrm{RBCL}$ ) en tanto el desarrollo de dicha actividad puede ser considerada como un uso común especial.

En estos casos, el margen de actuación de los Ayuntamientos a la hora de otorgar o no las correspondientes licencias debiera ser muy reducido, ya que ni la normativa estatal ni la autonómica dispone limitaciones, exigencias o requisitos concretos que deban ser tenidos en cuenta y conduzcan dicha decisión. De hecho, el propio art. 71 RBCL dispone que estas licencias deben otorgarse directamente salvo que sea necesaria la limitación del número de las mismas, a lo que se uniría el principio de intervención mínima frente al desarrollo de las actividades privadas que informa toda intervención municipal.

En tanto no se ha llevado a cabo una intervención municipal específica y dada la amplitud de lo dispuesto al respecto por parte de la normativa estatal y autonómica, pudiera considerarse que la actuación municipal ante las 
solicitudes debería ser el otorgamiento con carácter reglado de la licencia, siempre que no se perjudicase el interés general local o de terceros.

No obstante el propio título competencial de ordenación, gestión y protección del dominio público y otros títulos concomitantes relativos al orden público, la salubridad o al medio ambiente, habilitan a la autoridad municipal competente a denegar, restringir o condicionar discrecionalmente el otorgamiento de las licencias para el desarrollo de la actividad de distribución gratuita de prensa en la vía pública.

\section{ANÁLISIS DE LA ORDENACIÓN MUNICIPAL DE LA DISTRIBUCIÓN GRATUITA DE PRENSA EN LA VÍA PÚBLICA}

\subsection{Actividad objeto de regulación y sujetos implicados}

Las ordenanzas municipales reguladoras de la distribución gratuita de prensa, en aquellos municipios en los que existen, comienzan por delimitar su objeto, esto es, la actividad a la que se refieren y cuyo ejercicio regulan.

En este sentido, a pesar de lo concreto de la actividad, conviene configurar de forma amplia el objeto sometido a regulación, ya que, de otro modo, resultaría un norma excesivamente rígida que puede ser desbordada fácilmente. De hecho, en algún caso como es el de la Ordenanza Municipal de Valencia, el objeto se centra en la distribución gratuita de prensa diaria, lo que excluye de manera absurda la prensa con una periodicidad distinta.

Las ordenanzas no suelen especificar el objeto de su regulación ya que suelen referirse a la prensa, con carácter indeterminado, o de forma indiferenciada a los periódicos, revistas y otras publicaciones periódicas. Por lo general no suelen entrar a definir las características de estas publicaciones periódicas, es decir, si se trata de contenido informativo o no, o de elaboración propia o ajena, para evitar exclusiones innecesarias.

En cualquier caso, en desarrollo de lo previsto en el artículo 77 del Real Decreto, el ejercicio de la actividad a la que se refieran por lo general, la distribución gratuita de prensa en la vía y espacios públicos se somete a la previa obtención de licencia municipal, título que habilita para su ejercicio en las condiciones fijadas en la misma. Evidentemente estas licencias son personales e intransferibles y se refieren exclusivamente al aprovechamiento de la vía pública u otros espacios de dominio público sin perjuicio de las demás autorizaciones y requisitos exigibles por otras Administraciones competentes ${ }^{24}$.

\footnotetext{
${ }^{24}$ En tanto las licencias son actos administrativos de carácter personal, son intransmisibles tal y como lo disponen la ordenanzas y como lo prevé el propio art. 77 RBCL.
} 
LA INTERVENCIÓN MUNICIPAL SOBRE LA DISTRIBUCIÓN GRATUITA DE PRENSA...

Con respecto a los sujetos que pueden solicitar la licencia para el desarrollo de la actividad no existe más limitación que la capacidad de obrar, por lo que pueden solicitarlas tanto personas físicas como personas jurídicas. En este sentido se disponen requisitos para la identificación de los titulares orientándolos a las personas jurídicas que serán, por lo general, los titulares de las licencias ${ }^{25}$.

Se presupone la regularidad de la situación del solicitante por lo que respecta a sus obligaciones tributarias y relativas a la Seguridad Social, ya que se suele requerir la aportación del alta fiscal, así como el régimen de la Seguridad Social que le corresponda.

En este punto es necesario aclarar que se distingue entre la titularidad de la licencia y el desarrollo de la actividad, ya que ésta puede ejercerse por los propios titulares de forma directa o a través de personas contratadas por éstos conforme a la normativa laboral vigente. En este sentido las ordenanzas suelen incluir el requisito de la regularidad de los trabajadores asalariados que llevan a cabo el reparto, por lo que se suele exigir como requisito la aportación del DNI y alta en la Seguridad Social de las personas que ejerciten tal actividad en la vía pública. Asimismo se exige que los repartidores lleven visible una tarjeta identificativa expedida por el titular de la autorización.

Por último, en cuanto al órgano competente para resolver sobre las solicitudes de otorgamiento de las licencias será aquél establecido por la propia ordenanza o por la normativa de organización del Ayuntamiento.

En el caso de grandes municipios suele atribuirse esta competencia a los concejales-presidentes de las juntas municipales de distrito u órganos similares (Ayuntamiento de Madrid), a organismos especializados en el ámbito urbanístico como la Gerencia de Urbanismo (Ordenanza de Sevilla) o a la Junta de Gobierno (Málaga).

\subsection{Elementos espaciales: superficie ocupada y distancias de los emplazamientos}

La actividad de distribución gratuita de prensa deberá realizarse en los emplazamientos exactos que se indiquen en la correspondiente licencia, que se deberán adaptar a lo dispuesto en la respectiva ordenanza municipal o, en su caso, a lo que disponga el órgano competente en el otorgamiento de la misma.

\footnotetext{
${ }^{25}$ Las ordenanzas se limitan a señalar que las solicitudes pueden formularse por personas físicas o jurídicas titulares de la publicación, con plena capacidad jurídica y de obrar y constituidas conforme a derecho.
} 
Los emplazamientos se otorgan en función de la solicitud de los interesados en la medida que se adapten a las limitaciones, restricciones y condiciones establecidas.

Para la adecuada identificación de dichos emplazamientos y para el conocimiento de las circunstancias exactas en los que se pretende llevar a cabo la actividad de distribución gratuita de prensa, se suele exigir como documentación obligatoria que ha de acompañar a la solicitud una Memoria Justificativa en la que se describa la actividad y las condiciones en que pretende ejercerse, así como un Documento en el que se especifiquen los emplazamientos concretos que se solicitan por orden de preferencia, mediante su descripción suficiente y su identificación sobre mapas del municipio.

En cuanto a las limitaciones, restricciones, requisitos y condiciones establecidas por las ordenanzas municipales para el desarrollo de la actividad de distribución de prensa gratuita se pueden agrupar de la siguiente manera:

\section{a) Limitaciones, restricciones y condiciones cuantitativas del número de licencias, emplazamientos o personas autorizadas}

Si bien las ordenanzas no suelen reflejarlo expresamente, el número de emplazamientos o situados de cada titular puede limitarse, y así lo hace alguna señalando un máximo de 40 por cada solicitante (30 en otras). El número de licencias puede limitarse en el caso que se considere que el municipio se encuentra saturado por el número licencias adjudicadas o por cualquier otra razón de interés general. Así lo prevén algunas ordenanzas municipales (Zaragoza), que incluso señalan como límite de saturación el número de 80 puntos de reparto en toda la ciudad. En caso de que no esté previsto en las propias ordenanzas se podría igualmente llevar a cabo una restricción total o parcial (por zonas) del otorgamiento de licencias siempre que esté suficientemente motivado y responda al interés general.

Asimismo pueden coincidir varias solicitudes en unos mismos emplazamientos o situados, que por lo general no tienen por qué resultar incompatibles, por lo que las propias ordenanzas suelen prever la autorización simultánea de distintos solicitantes en un mismo emplazamiento, e incluso de más en el caso de que se encuentre justificado. En la medida que se produzca una concurrencia de solicitudes y no resulte posible atender todas por razones motivadas, se aplicará lo dispuesto en la ordenanza municipal correspondiente, que responderá a lo previsto en el art. 77 RBCL que contempla en estos casos la adjudicación mediante sorteo.

Por el contrario, se restringe la posibilidad de situar en un mismo emplazamiento más de dos repartidores por un mismo interesado salvo autorización excepcional por razón de la intensidad del tránsito peatonal. 
LA INTERVENCIÓN MUNICIPAL SOBRE LA DISTRIBUCIÓN GRATUITA DE PRENSA...

En sentido inverso a todas las medias señaladas hasta ahora tendentes a restringir y limitar los emplazamientos, existen ordenanzas que incluyen medidas para el reparto homogéneo de los puntos de distribución, de manera que se desconcentre y que garantice el reparto en todo el territorio municipal, por lo que aflora el carácter de servicio público que subyace al ejercicio de esta actividad y que no siempre es bien percibido. Así se prevé en la Ordenanza de Zaragoza que establece que la distribución de los puntos de reparto se efectuará de modo que exista al menos uno en las cuatro quintas partes de los distritos urbanos de la ciudad, y que en dos quintos de tales distritos, como máximo, dicha obligación puede entenderse cumplida si se pone a disposición del público la publicación a través de quioscos u otros establecimientos dedicados a la venta de prensa.

\section{b) Limitaciones y restricciones relativas a la ubicación de los puntos de distribución dentro del territorio municipal}

Las ordenanzas municipales contienen prohibiciones y limitaciones a la distribución gratuita de prensa con respecto a determinados espacios por las siguientes razones:

1. Por la posible obstaculización del tránsito peatonal o la circulación vehículos: se prohíbe el reparto en la calzada, en badenes o en la confluencia de los pasos de peatones con las aceras, en aceras de menos de 3 metros, en las paradas o en el interior de vehículos de transporte público, desde vehículos o a personas que se encuentren en el interior de ellos, y, en general, en puntos en los que se dificulte la utilización de cualquier elemento de servicios o mobiliario urbano sitos en las vías públicas o se entorpezca la visibilidad del tráfico.

2. Por la posible obstaculización en los accesos a determinados lugares especialmente transitados: así son los lugares de acceso a transportes públicos (paradas de autobús, acceso a estaciones, bocas de metro), acceso a establecimientos mercantiles o industriales, y, en general, puntos que obstaculicen el acceso a edificios o lugares públicos.

3. Por tratarse de entornos que merecen una especial protección por su valor histórico-artístico o ambiental: se prohíbe en parques y jardines, o delante o junto a museos, edificios o monumentos que integren el patrimonio histórico-artístico de la ciudad, salvo autorización específica.

4. Por entrar en conflicto con otras autorizaciones, licencias y permisos para actividades análogas: a menos de 50 metros (75 en determinados casos) de distancia -medidos en recorrido peatonal- de quioscos o locales dedicados exclusiva o preferentemente a la venta de pren- 
sa, o de sedes, oficinas o centros de trabajo de otros medios de comunicación.

\section{c) Condiciones físicas del punto de distribución}

Si bien las condiciones de distribución de cada punto se hacen constar en las licencias que se otorguen, éstas deben adaptarse a lo dispuesto, en su caso, en las correspondientes ordenanzas municipales.

En todas éstas se restringe la utilización de mesas, caballetes, sillas o cualquier otro instrumento, previendo únicamente la posibilidad de utilizar instalaciones indispensables para el reparto que deben ser móviles o semovientes ya que, de ser instalaciones fijas supondría un uso privativo del dominio público que conlleva la obtención de concesión administrativa.

Asimismo se establecen las características físicas de estas instalaciones coincidiendo en las medidas máximas de la superficie a ocupar (suele ser 0'50 de ancho, 0'50 de largo y 1'20 de alto).

\subsection{Elementos temporales: días y horas de reparto}

La mayoría de las ordenanzas municipales fijan como calendario de distribución de lunes a viernes excepto los días de fiesta nacional, y como horario de distribución entre las 7 y las 11, si bien en algún caso se prevé el reparto vespertino de 17 a 21 (Ordenanza Madrid). Asimismo se suelen incluir excepciones previendo la posibilidad de autorizar el reparto en días festivos o en horarios distintos previa justificación basada en las características de la publicación o del lugar de distribución.

La rigidez de los horarios de reparto, a pesar de las excepciones, pone de manifiesto una cierta rigidez en la adaptación a las nuevas manifestaciones de la prensa de distribución gratuita ya que existen publicaciones vespertinas (como el diario de información general "Ahora" de reciente aparición) y otras destinadas a espectáculos deportivos y taurinos que se suelen celebrar en fines de semana y normalmente por la tarde.

En este sentido, se hace evidente la necesidad de introducir una flexibilización en los días y las horas de distribución de manera que se adapten a las características de la publicación sin que ello suponga una eliminación de la racionalización que se pretende con las limitaciones temporales.

Entretanto la flexibilidad debe venir de la aplicación de estas ordenanzas ya que la aplicación rigurosa de las previsiones de la mayoría de las ordenanzas existentes conduciría a una limitación inaceptable del derecho de 
LA INTERVENCIÓN MUNICIPAL SOBRE LA DISTRIBUCIÓN GRATUITA DE PRENSA...

comunicación, ya que excluiría la posibilidad de su ejercicio en todas aquellas publicaciones que, como las señaladas, sólo tienen sentido fuera del calendario y del horario marcado por las ordenanzas. De hecho, las denegaciones de las autorizaciones por este motivo podría implicar la nulidad de pleno derecho de las mismas por vulneración de derechos fundamentales.

\subsection{Elementos funcionales: desarrollo de la actividad de distribución y reparto}

En el desarrollo de la actividad debe distinguirse el suministro de ejemplares a los emplazamientos o situados (que no sería considerada distribución), y la distribución y/o reparto que se lleva a cabo en cada uno de éstos. Este último se debe llevar a cabo de forma manual prohibiéndose en todas la ordenanzas el simple depósito de ejemplares para su retirada por parte de los ciudadanos.

La actividad de suministro de los ejemplares a los puntos autorizados no está específicamente regulada, por lo que se somete a la normativa general sobre tráfico o sobre carga y descarga de mercancías en el caso de que exista.

Con respecto a la actividad de distribución y reparto en cada uno de los emplazamientos autorizados se establecen una serie de prohibiciones y limitaciones.

Se prohíbe así la distribución ambulante, por lo que sólo podrá realizarse desde el lugar específicamente autorizado no pudiendo desplazarse las personas que ejerzan la actividad fuera de un radio de acción del personal para el reparto, establecido normalmente en 5 metros en torno al punto autorizado.

En cuanto a la utilización de instalaciones para el desarrollo de la actividad de distribución y reparto, suele restringirse el uso de mesas, caballetes, banquetas, etc. si bien se prevé que se pueda utilizar carritos u otros instrumentos para el transporte y depósito de los ejemplares a distribuir que deberán cumplir las características físicas que se establezcan.

En el ejercicio de la actividad no puede anunciarse el reparto a través de medios sonoros, ya sean artificiales (altavoces, amplificadores o cualquier otro aparato emisor) o la propia voz. También con respecto a la publicitación de la publicación repartida se prevé que si bien los repartidores pueden exhibir en su ropa publicidad de la propia publicación distribuida, la exhibición o realización de cualquier otro tipo de publicidad se somete a lo establecido con respecto a la actividad publicitaria.

Por último, se contempla una obligación de limpieza y mantenimiento del punto adjudicado, por lo que los periódicos no podrán en ningún caso ser abandonados en la vía pública. Además se añade que todo repartidor o, en 
su caso, suministrador están obligados a recoger los ejemplares esparcidos en un radio de 10 metros desde el punto de distribución autorizado. Asimismo deberán recoger y retirar para su eliminación en forma adecuada todo material de desecho o residuos, tales como envoltorios, papeles, flejes u otros.

En cualquier caso, el desarrollo de la actividad por parte de los repartidores siempre se encuentra sometido, además de a las condiciones establecidas en la licencia, a las instrucciones que para su correcto desarrollo puedan dictar los agentes de policía local.

\subsection{Derechos y obligaciones de los titulares de las licencias}

Las licencias otorgadas confieren el derecho a sus titulares de efectuar la distribución de prensa en las condiciones establecidas en ella misma y las resultantes de las respectivas ordenanzas y del resto de la normativa aplicable.

Más allá de este derecho genérico al desarrollo de la actividad de distribución de prensa gratuita en la vía pública sobre los titulares de las licencias pesan, ante todo, obligaciones que se derivan principalmente de las limitaciones, restricciones y condiciones que imponen al ejercicio de dicha actividad por las propias ordenanzas municipales o bien que se concretan en las licencias otorgadas.

Al margen de estas obligaciones relativas al ejercicio de la propia actividad, podemos identificar algunas obligaciones accesorias como son la de constituir fianza por el importe que se establezca, normalmente a través de la correspondiente ordenanza fiscal, para responder del cumplimiento de las obligaciones inherentes a la licencia. El importe de esta fianza se establece y actualiza a través de las ordenanzas fiscales ${ }^{26}$.

Junto a la constitución de la fianza se incorpora al otorgamiento de las licencias el cobro de unas tasas por la utilización del dominio público, por lo que las licencias de distribución gratuita de prensa pasan a engrosar los medios de financiación de las haciendas locales.

Efectivamente, conforme a las facultades que le concede el artículo 133.2 y $142 \mathrm{CE}$ y el artículo $10 \mathrm{LBRL}$, y de conformidad con lo dispuesto en los artículos 15 a 19 del Real Decreto Legislativo 2/2004, de 5 de marzo, por el que se aprueba el texto refundido de la Ley Reguladora de las Haciendas Locales, los Ayuntamientos pueden establecer tasas por el otorgamiento de autorizaciones para la distribución gratuita de prensa, en la medida que constituye una ocupación del dominio público.

\footnotetext{
${ }^{26}$ En el caso de Zaragoza, la fianza dispuesta en el año 2006 para cada licencia es de 3182, 70 euros.
} 
LA INTERVENCIÓN MUNICIPAL SOBRE LA DISTRIBUCIÓN GRATUITA DE PRENSA...

En este sentido la ocupación de la vía pública para el reparto gratuito de prensa entra dentro de los supuestos contemplados en el artículo 20 del Real Decreto Legislativo 2/2004, que habilita a las entidades locales a establecer tasas por la utilización privativa o el aprovechamiento especial del dominio público local, así como por la prestación de servicios públicos o la realización de actividades administrativas de competencia local que se refieran, afecten o beneficien de modo particular a los sujetos pasivos.

Es necesario que el Ayuntamiento correspondiente apruebe mediante Ordenanza Fiscal la regulación de la tasa por la distribución gratuita de prensa en la vía pública, estableciendo como hecho imponible la ocupación de dominio público, y definiendo los obligados tributarios, la base imponible y las tarifas de la misma ${ }^{27}$.

\subsection{Otorgamiento, duración y extinción de las licencias}

El otorgamiento de estas licencias tiene carácter discrecional y se hace a título de precario. Así lo expresan algunas de las ordenanzas que manifiestan expresamente este carácter (Ordenanza Zaragoza y Málaga), y, así se deduce de lo dispuesto por la normativa estatal y autonómica sobre utilización del dominio público en régimen de común especial, cuyo uso está condicionado a la concreción de la preceptiva licencia conforme a lo dispuesto en los artículos 74, 75 y, en particular 77 RBCL como señala la Sentencia del Tribunal Supremo (Sala de lo Contencioso-administrativo) de 29 de noviembre de 2000.

Este sometimiento del uso del dominio público vial a la discrecionalidad de las Administraciones Locales viene confirmada por una reiterada jurisprudencia que concibe la utilización del mismo como un acto unilateral de tolerancia por parte de la Administración, por lo que no existe un derecho subjetivo a la utilización del dominio público (Sentencia del Tribunal Supremo de 6 de julio y 25 de septiembre de 1981, y de 26 de febrero de 1990).

Este carácter discrecional se aplica incluso en el caso de los municipios que hayan aprobado ordenanzas relativas a la distribución gratuita de prensa o al uso y ocupación del dominio público en general ya que, en estos casos se pueden distinguir aspectos reglados en el otorgamiento de las licencias, en la medida que las solicitudes cumplan con los requisitos y exigencias

\footnotetext{
${ }^{27}$ En el caso de Madrid para el año 2006, por cada situado o lugar de reparto, cuando la autorización es anual, para días laborables, en horario sólo de mañana o sólo de tarde y para un único repartidor se establecen tarifas que oscilan entre los 328,44 euros y los 12,75 en función de la categoría de la calle. Estas tarifas se pueden ver modificadas, atendiendo al alcance de la autorización correspondiente, por la aplicación de los coeficientes que dependen del horario autorizado, de si se permite en días festivos, si se faculta al reparto simultáneo por varios repartidores en el mismo situado.
} 
dispuestos en la propia Ordenanza, si bien fuera del cumplimiento de dichos parámetros se mantiene un ámbito de discrecionalidad en el otorgamiento de las licencias.

Evidentemente estas decisiones discrecionales se encuentran sometidas al correspondiente control judicial que permite a los órganos jurisdiccionales entrar a revisarlas conforme a los principios jurisprudenciales decantados a este respecto ${ }^{28}$.

Por último, por lo que respecta al otorgamiento de estas licencias conviene señalar que, en tanto no se establezca duración específica del procedimiento de otorgamiento en la Ordenanzas, el máximo para resolver será de tres meses, transcurridos los cuales sin respuesta por parte del Ayuntamiento darán lugar a un silencio negativo en tanto la estimación de la solicitud supondría la transferencia al solicitante de facultades relativas al dominio público (arts. 42.3 y 43.3 LRJ-PAC).

En cuanto a la duración de las licencias es necesario que tengan una duración determinada. Por lo tanto se prevén distintos supuestos de duración de las autorizaciones para la distribución gratuita de prensa, que van desde la posibilidad de optar entre seis meses o un año (como es el caso de Madrid), si bien en la mayoría de los municipios el otorgamiento se produce por años naturales (Sevilla, Valencia, Zaragoza) estableciéndose en estos casos un período para la presentación de solicitudes (unos meses antes del comienzo del mismo) que no afectaría al año en que la publicación comienza su actividad.

Junto a la duración se prevé un mecanismo de prórroga automática del plazo de validez de la licencia a solicitud de los interesados, a veces con limitación del número consecutivo de renovaciones (cuatro en el caso de $\mathrm{Za}$ ragoza y Sevilla) que obliga a solicitar de nuevo la autorización. En otros casos, si bien no se prevé la renovación automática de la autorización, sí se facilita la solicitud continuada de las autorizaciones para aquellos interesados que ya la hubiesen obtenido en años anteriores de manera que sólo tengan que indicar los aspectos que difieren de una a otra solicitud.

En cualquier caso, a efectos de la renovación y tal como lo expresan algunas ordenanzas, el otorgamiento no origina derecho preferente ni de nin-

\footnotetext{
${ }^{28}$ Es necesario recordar los límites de la discrecionalidad ya que, como dice el Tribunal Constitucionalidad en las sentencia 325/1994, de 12 diciembre y 264/2000, de 13 noviembre, la arbitrariedad no debe confundirse con la discrecionalidad o facultad de elegir entre dos soluciones igualmente legales. Aquélla consiste en la carencia de fundamento alguno, ni de razón o experiencia, convirtiendo en caprichoso el comportamiento humano, cuyas pautas han de ser la racionalidad, la coherencia y la objetividad. Por lo tanto, puede someterse a control de legalidad la decisión de otorgar o no las licencias y las condiciones en que éstas se otorgan considerando si en dicha actuación discrecional se dan esas notas de discrecionalidad o, por el contrario, se ha dado lugar a una solución diferente, basada en el mero voluntarismo o con expresión de un proceso deductivo irracional o absurdo (SSTC 160/1997, de 2 octubre, fj. 7; 82/2002, de 22 abril, fj 7; y 125/2004, de 19 julio, fj 5.).
} 
LA INTERVENCIÓN MUNICIPAL SOBRE LA DISTRIBUCIÓN GRATUITA DE PRENSA...

guna naturaleza para la obtención de autorización, licencia o concesiones futuras, ni sobre los puntos de distribución autorizados.

Las licencias se extinguen por el transcurso del plazo autorizado (salvo prórroga), por renuncia del titular, por revocación al desaparecer las circunstancias que motivaron su otorgamiento o sobrevinieran otras y revocación por incumplimiento de los requisitos establecidos para su otorgamiento y las condiciones que los motivaron.

En el primer supuesto la extinción se produce de forma automática, en los demás la extinción de la licencia se producirá una vez incoado el expediente administrativo correspondiente a tal efecto, en el que se debe dar audiencia al titular.

Además de la extinción, se prevé otros supuestos de alteración de la vigencia normal de las licencias, como son la suspensión y la modificación de la licencias. Estos supuestos se pueden producir en cualquier momento por razón de interés público, que debe ser acreditado.

La revocación, suspensión o modificación no puede ser arbitraria sino que debe responder a motivos fundamentados como algunos señalados en las propias ordenanzas, entre los que figuran que resulten incompatibles con las condiciones generales aprobadas con posterioridad, produzcan daños en el dominio público, impidan su utilización para actividades de mayor interés público o menoscaben el uso general (Valencia).

En tanto el otorgamiento de la licencia se produce a título de precario, la extinción por revocación o incumplimiento, la suspensión y la modificación de las licencias no genera derecho a ningún tipo de indemnización. Así lo disponen todas las ordenanzas municipales, tal y como se reconoce en la jurisprudencia ${ }^{29}$.

No obstante, cuando la revocación responda a un cambio de criterio de apreciación del órgano otorgante, sí se deberán resarcir los daños y perjuicios que se causaren, tal y como dispone el art. 16.3 RSCL y reconoce la jurisprudencia en supuestos como suprimir el otorgamiento de licencias en determinados espacios ${ }^{30}$.

\subsection{Régimen sancionador}

Las ordenanzas municipales reguladoras de la distribución gratuita de prensa en la vía pública se completan con un régimen sancionador específi-

\footnotetext{
${ }^{29}$ Vid. por todas, la Sentencia del Tribunal Supremo (Sala de lo Contencioso-administrativo) de 29 de noviembre de 2000).

${ }^{30}$ Así la Sentencia del Tribunal Supremo de 8 de febrero de 2002.
} 
co, que se introduce bajo la cobertura de lo dispuesto en el Título XI de la LBRL sobre Tipificación de las Infracciones y Sanciones por las Entidades Locales en Determinadas Materias, que fue introducido por la Ley 57/2003, de 16 de diciembre, de medidas para la modernización del gobierno local.

Se tipifican como leves, graves o muy graves diversas infracciones relativas a las medidas dispuestas en el contenido de las propias ordenanzas.

Al margen de las infracciones leves, podemos seguir lo dispuesto en la Ordenanza de Zaragoza como ejemplo que tipifica como infracción muy grave la comisión de tres o más faltas graves en un año, el no abonar las tasas correspondientes por la ocupación de la vía pública en los términos establecidos en la ordenanza fiscal, el reparto de la prensa sin la preceptiva licencia municipal o el llevar a cabo la ocupación de la vía pública de forma que se obstaculice el tránsito peatonal o rodado.

En cuanto a las infracciones graves se incluye el ejercer la actividad en puntos no autorizados, utilizar los elementos de mobiliario urbano o cualquier otro soporte no autorizado como elemento de apoyo o para el depósito de los periódicos, reparto de prensa a los ocupantes de vehículos o en los transportes públicos, así como el reparto desde vehículos estacionados o en movimiento, molestar a los viandantes e impedir el libre tránsito peatonal, el anuncio de la distribución gratuita de prensa mediante voceo o a través de la utilización de cualquier elemento de amplificación acústica, la falta de ornato o limpieza del lugar destinado a la distribución con ocasión del ejercicio de la actividad autorizada.

Las sanciones oscilan en función del tipo de infracción cometida y de la gravedad de la misma desde los 150 a los 900 euros en Zaragoza, igualmente de 700 a 3.000 euros en Valencia, y de 60 a 30.050 euros (cantidad sorprendentemente elevada) en el caso de Madrid. Junto a las sanciones pecuniarias se incluyen otro tipo de sanciones accesorias como la revocación de la licencia o el no otorgamiento de nuevas autorizaciones en un periodo de 2 años.

Los agentes de la Policía Local son los encargados de desarrollar las funciones de inspección y vigilancia, cuidando del cumplimiento de las ordenanzas.

\section{EL EQUILIBRIO ENTRE LA INTERVENCIÓN MUNICIPAL SOBRE LA DISTRIBUCIÓN GRATUITA DE PRENSA Y EL EJERCICIO DE LOS DERECHOS FUNDAMENTALES DE LA COMUNICACIÓN}

Una vez considerados los fundamentos de la intervención municipal sobre la distribución gratuita de prensa en la vía pública y descrito el conteni- 
LA INTERVENCIÓN MUNICIPAL SOBRE LA DISTRIBUCIÓN GRATUITA DE PRENSA...

do de la misma, no cabe duda de que ésta incide sobre el ejercicio de los derechos fundamentales de la comunicación.

Efectivamente, la distribución gratuita de las publicaciones periódicas es una actividad que se encuentra directamente relacionada con el derecho de comunicación y condiciona y restringe su ejercicio. En este sentido es posible afirmar que la distribución de publicaciones periódicas forma parte del contenido esencial de los derechos de comunicación reconocidos en el artículo 20.1 a) y $20.2 \mathrm{CE}$.

Así se deduce de la Sentencia del Tribunal Constitucional 52/1995, de 23 de febrero de 1995, que otorga el amparo a un recurso frente a unos actos (Resoluciones de la Jefatura Provincial de Comunicaciones de Barcelona de 18 y 28 de octubre de 1982 y de 22 de septiembre de 1983), que aplicaban un reglamento (Real Decreto 1189/1982) como único fundamento jurídico para la denegación del acceso al servicio de Correos de las publicaciones de las que la actora era editora negando el derecho de distribución mediante envío de paquetes postales de sus revistas.

En dicha sentencia (Fundamento Jurídico 2), el Tribunal Constitucional afirma que con la distribución de publicaciones periódicas mediante correo $\mathrm{y}$, por lo tanto, mutatis mutandi, con la distribución gratuita de prensa en la vía pública, se está ejerciendo el derecho de comunicación reconocido en el artículo $20 \mathrm{CE}$ pues «el propio Texto constitucional se hace eco de esta vertiente del derecho considerado, al reconocer expresamente como contenido de éste la "difusión" de las ideas y opiniones y al articular explícitas garantías frente al secuestro de publicaciones. Por consiguiente la restricción del uso del servicio de correos de una publicación periódica afecta al derecho fundamental a la libertad de expresión, y por ello puede examinarse la licitud de esa restricción desde la perspectiva del respeto del derecho fundamental».

Si bien la distribución de publicaciones forma parte del derecho fundamental de comunicación, no obstante debe recordarse que su ejercicio no puede llevarse a cabo de manera libre e incondicionada sino dentro de los límites necesarios que resultan de su propia naturaleza, con independencia de los que se producen por su articulación con otros derechos o de los que, respetando siempre su contenido esencial, pueda establecer el legislador (Sentencia del Tribunal Constitucional de 13 de febrero de 1981, STC 5/1981).

Por lo tanto, es posible que se establezcan límites a la actividad de distribución de prensa gratuita en la vía pública, siempre y cuando dichos límites respeten el contenido esencial del derecho de comunicación que se ejercita y que dichas limitaciones se deriven de una norma con rango de Ley. Estas son las dos condiciones que se deben respetar para alcanzar un equilibrio entre la ordenación municipal de la distribución gratuita de prensa en la vía pública y el respeto al ejercicio de derecho fundamental de comunicación. 
Por lo que respecta al contenido esencial, este ha sido reiteradamente definido por la jurisprudencia constitucional como aquella parte del contenido del derecho que es absolutamente necesaria para que los intereses jurídicamente protegibles, que dan vida al derecho, resulten real, concreta y efectivamente protegidos. En el caso del derecho de comunicación y la libertad de expresión este contenido esencial se traduce en que, de acuerdo con la naturaleza del medio a través del cual se expresen dichas ideas y opiniones, sea posible la difusión de éstas, permitiendo su acceso a terceros destinatarios de las mismas.

En estos términos no cabe establecer por los Ayuntamientos una restricción absoluta de la distribución de prensa en el municipio. No obstante cabe la imposición de limitaciones parciales, restricciones y condiciones como las que, de hecho, figuran en las ordenanzas existentes sobre distribución gratuita de prensa, siempre y cuando estén justificadas por la propia naturaleza de la actividad, por el ejercicio de otros titulares de este derecho y por su articulación con otros derechos y, en todo caso, permitan su difusión.

Si bien no resulta posible establecer unos criterios concretos relativos al alcance de la intervención municipal sobre la distribución de prensa, sí es posible afirmar que, teniendo en cuenta las circunstancias señaladas debe ser una intervención de mínimos ya que, en cualquier caso, se trata de medidas que constituyen obstáculos a la difusión de publicaciones y, por tanto, tienen un alcance restrictivo del derecho de comunicación y a la libertad de expresión. En este sentido, debería tratarse de una regulación que garantizase los intereses presentes en la utilización del dominio público vial con la menor incidencia posible en el ejercicio de un derecho fundamental como es la distribución gratuita de prensa. Sobre todo deberían evitarse regulaciones excesivamente detalladas ya que así se evitarían elementos de rigidez a la hora de afrontar el futuro de esta actividad, que si llegan a resultar excesivos podrían considerarse limitaciones inconstitucionales de la misma ${ }^{31}$.

En cuanto a la cuestión de la reserva de ley para la imposición de límites al ejercicio de los derechos fundamentales que dispone el artículo 53.1 CE, se plantea el problema de la incapacidad de los Ayuntamientos para establecer dichas limitaciones a través de sus ordenanzas.

Con respecto a la reserva de ley exigida para la imposición de limitaciones al derecho de comunicación y la libertad de expresión, la sentencia del Tribunal Constitucional núm. 52/1995 mencionada, señala que la garantía formal de estos derechos descansa sobre el rango de la norma que autorice

\footnotetext{
${ }^{31}$ Piénsese, por ejemplo, en la restricción a la distribución en horario de 9 a 11 que se dispone en alguna Ordenanza; tal y como ha evolucionado la llamada prensa gratuita, con la aparición de publicaciones vespertinas, resulta excesiva una limitación a este horario que imposibilitaría el desarrollo de la actividad a estas publicaciones vespertinas, afectando a su derecho a la comunicación y a la libre expresión.
} 
LA INTERVENCIÓN MUNICIPAL SOBRE LA DISTRIBUCIÓN GRATUITA DE PRENSA...

al poder público de que se trate a adoptar una medida con alcance restrictivo del derecho consagrado en el artículo 20.1 a) CE, conforme exige el artículo 53.1 CE.

Para salvar una interpretación excesivamente restrictiva de la necesidad de reserva de ley necesaria para la limitación de derechos fundamentales que dejaría inoperantes a las entidades locales afectando a su autonomía, se hace necesario considerar que, en tanto se trata de una limitación indirecta al ejercicio de un derecho fundamental, dicha limitación se puede concretar a través de reglamentos siempre que éstos cuenten con la cobertura suficiente de una norma con rango de ley.

En el caso de las ordenanzas municipales de distribución gratuita de prensa en la vía pública, si bien resultaría insuficiente el RBCL, se ha de tener en cuenta que traen causa, en última instancia, de la LPAP y de la LBRL que constituyen normas de rango legal suficiente para que los Ayuntamientos puedan dictar reglamentos de desarrollo como son las ordenanzas municipales sobre distribución gratuita de prensa.

En definitiva, se hace necesario alcanzar un equilibrio adecuado entre la intervención municipal sobre la distribución gratuita de prensa en la vía pública y el ejercicio de los derechos fundamentales a la comunicación y a la libertad de expresión, para lo que resulta recomendable articular dicha intervención a través de ordenanzas municipales reducidas, flexibles y genéricas que no contengan una regulación casuística y detallada que quedaría rápidamente desfasada por su incapacidad para adaptarse a las nuevas situaciones.

Pero esto no debe significar una pérdida de garantías para el ejercicio de los derechos fundamentales de la comunicación y la expresión al quedar expuesto a la discrecionalidad de los propios Ayuntamientos, ya que las garantías quedarían formuladas en las cláusulas de carácter general.

El punto de equilibrio se encuentra en la consecución de una regulación suficiente para que la actividad de distribución gratuita de prensa no afecte a los intereses generales vinculados al dominio público vial, y que la ordenación que se apruebe no constriña excesivamente el ejercicio de dicha actividad y que pueda adaptarse a un ámbito social cambiante que produce fenómenos como el de la propia prensa gratuita. 